\title{
Supramolecular assembly of 2-aminobenzothiazole and $N$-[(2-oxo- 2H-1-benzopyran-3-yl)carboxyl]phenethylamide donor-acceptor complex. A comparative study
}

\author{
Efrén V. García-Báez, ${ }^{a}$ Francisco J. Martínez-Martínez, ${ }^{a}$ Herbert Höpfl ${ }^{b}$, \\ and Itzia I. Padilla-Martínez ${ }^{* a}$ \\ ${ }^{a}$ Departamento de Química Unidad Profesional Interdisciplinaria de Biotecnología del IPN, Av. \\ Acueducto s/n Barrio la Laguna Ticomán, México D. F. 07340, México \\ ${ }^{b}$ Centro de Investigaciones Químicas, Universidad Autónoma del Estado de Morelos, \\ Cuernavaca Morelos, México \\ E-mail: ipadilla@acei.upibi.ipn.mx
}

(received 28 Aug 03; accepted 20 Nov 03; published on the web 25 Nov 03)

\begin{abstract}
In this paper the synthesis and solid state characterization of the donor-acceptor (D-A) complex between 2-aminobenzothiazole (ABT) and $\mathrm{N}$-[(2-oxo-2H-1-benzopyran-3yl)carboxyl]phenethylamide is reported. A comparison is performed with other aminobenzothiazole-coumarin complexes reported earlier and the results are analyzed in the context of crystal engineering. A common feature of these structures is the presence of a building block formed by pair-wise self complementary $\mathrm{NH} \cdots \mathrm{N}$ interactions between two molecules of ABT, defining an $\mathrm{R}_{2}^{2}(8)$ motif. The complete three-dimensional supramolecular arrangement is achieved by both strong $(\mathrm{NH} \cdots \mathrm{O})$ and weak $\left(\mathrm{CH}^{\cdots} \mathrm{X}, \mathrm{X}=\mathrm{O}\right.$, aryl $) \mathrm{H}$-bonding interactions which define an $A \cdots D \cdots D{ }^{\prime} \cdots A^{\prime}$ hydrogen bonded tetrameric unit, which packs through $\pi$-stacking interactions. The resulting donor-acceptor assemblies present two patterns of alternated stacking: D-A and D-A-A'-D'. Finally, the factors ruling the supramolecular isomerism exhibited by these complexes and the nature of the interactions are discussed and supported by ab initio theoretical calculations.
\end{abstract}

Keywords: 3-Carboxycoumarins, 2-aminobenzothiazole, $\pi$-stacking, donor-acceptor complexes, hydrogen bonding

\section{Introduction}

The design of supramolecular structures using crystal engineering involves molecules as building blocks and intermolecular non-covalent interactions as driving, directional and cohesive forces. ${ }^{1}$ Thereby, conventional hydrogen bonding has been recognized long ago as being of fundamental importance in determining the supramolecular arrangement in organic solids. ${ }^{2}$ Less explored are 
the weaker $\mathrm{C}-\mathrm{H} \cdots \mathrm{X}(\mathrm{X}=\mathrm{N}, \mathrm{O} \text {, Aryl })^{3}$ and $\pi \cdots \pi$-stacking interactions between high electron density and low electron density planar aromatic ring systems. ${ }^{4}$ Through space interactions between aromatic molecules represent an important class of intermolecular non-covalent interactions in chemistry, materials science and biology. ${ }^{5}$ Since they control a variety of molecular recognition processes, and self assembly phenomena, ${ }^{6}$ they have been applied in template directed synthesis in stereoselective organic reactions and in photochemical reactions in the solid state. ${ }^{7}$

Coumarins are planar aromatic heterocycles widely recognized because of their therapeutic properties as anticoagulant, spasmolytic, diuretic, anthelmintic and hypoglucemic agents. ${ }^{8}$ Specific inhibitory activities of 3-carboxy derivatives have been reported for tautomerase, elastase $^{10}$ and $\alpha$ chymotrypsin. ${ }^{11}$ Coumarins are known to bind to a wide variety of macromolecules, however, so far little is known about the forces that dominate the molecular recognition interactions involved. The ability to predict a crystal structure on the basis of a molecular structure has been very useful for the control of solid-state reactivity. In this sense the topochemistry of coumarins photodimerization has been controlled by the formation of a supramolecular aggregate between these molecules and $\beta$-cyclodextrins. ${ }^{12}$

In a previous publication it has been demonstrated that 3-carboxy coumarins self associate through $\pi$-stacking interactions. ${ }^{13}$ In this work the supramolecular structure of the title complex 3, formed between 2-aminobenzothiazole 1 as donor and $\mathrm{N}$-[(2-oxo-2H-1-benzopyran-3yl)carboxyl]phenethylamide 2a as acceptor, is reported. Because of the structural similarities between 1 and certain natural bases found in DNA (A, G and C have exo- $\mathrm{NH}_{2}$ groups and $\mathrm{N}$ atoms and/or NH units in their ring systems), the study of the supramolecular unit present in the lattice studied herein could be an aid for the better understanding of the intermolecular forces, which direct the molecular recognition of coumarin derivatives in the cell active sites. ${ }^{8,14}$
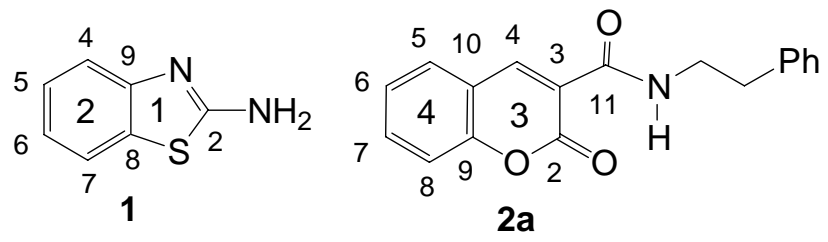

3 Complex between 1 and $\mathbf{2 a}$

\section{Results and Discussion}

\section{Electronic spectrum}

Upon combination of the colorless molecules $\mathbf{1}$ and 2a the yellow donor-acceptor complex 3 is formed. A change in color is generally in accordance with donor-acceptor associations (D-A) ${ }^{15}$ However, a more conclusive evidence is given by the charge transfer band measured at $406 \mathrm{~nm}$ 
in the solid phase, which was obtained by digital subtraction from the electronic spectra of the individual components. ${ }^{16}$

\section{Crystal structure of complex 3}

The supramolecular structure of complex 3 is depicted in Figure 1, where the synperiplanar conformation between the double bond and the carboxyamido carbonyl of the acceptor molecule can be appreciated $\left(\mathrm{C} 4-\mathrm{C} 3-\mathrm{C} 11-\mathrm{O} 11\right.$ torsion angle of $\left.2.1(3)^{\circ}\right)$. This conformation is presumably imposed by the $\mathrm{N} 12-\mathrm{H} \cdots \mathrm{O} 2$ hydrogen bonding interaction, whose graph set descriptor corresponds to an $\mathrm{S}(6)$ intramolecular ring. The geometry of the hydrogen bonding interactions are listed in Table 1 . The graph set notation $\mathrm{G}_{d}^{a}(G=\mathrm{S}$ for intramolecular rings, $\mathrm{R}$ for rings, $\mathrm{C}$ for chains and $\mathrm{D}$ for discrete patterns; $a=$ number of acceptors, $d=$ number of donors involved in H-bonding and $\mathrm{n}=$ number of atoms in the pattern) is used to describe the $\mathrm{H}$ bonding patterns reported in this paper. ${ }^{17}$ The donor and acceptor molecules are associated through N22- $\mathrm{H} \cdots \mathrm{O} 11$ hydrogen bonding interactions. Besides, two donor molecules form an $\mathrm{R}_{2}^{2}(8)$ ring through complementary $\mathrm{N} 22-\mathrm{H} \cdots \mathrm{N} 23$ interactions to form, the symmetric A $\cdots D^{\cdots} \cdots D^{\prime} \cdots A^{\prime}$ pseudotetramer located in plane [122] and depicted in Figure 1.

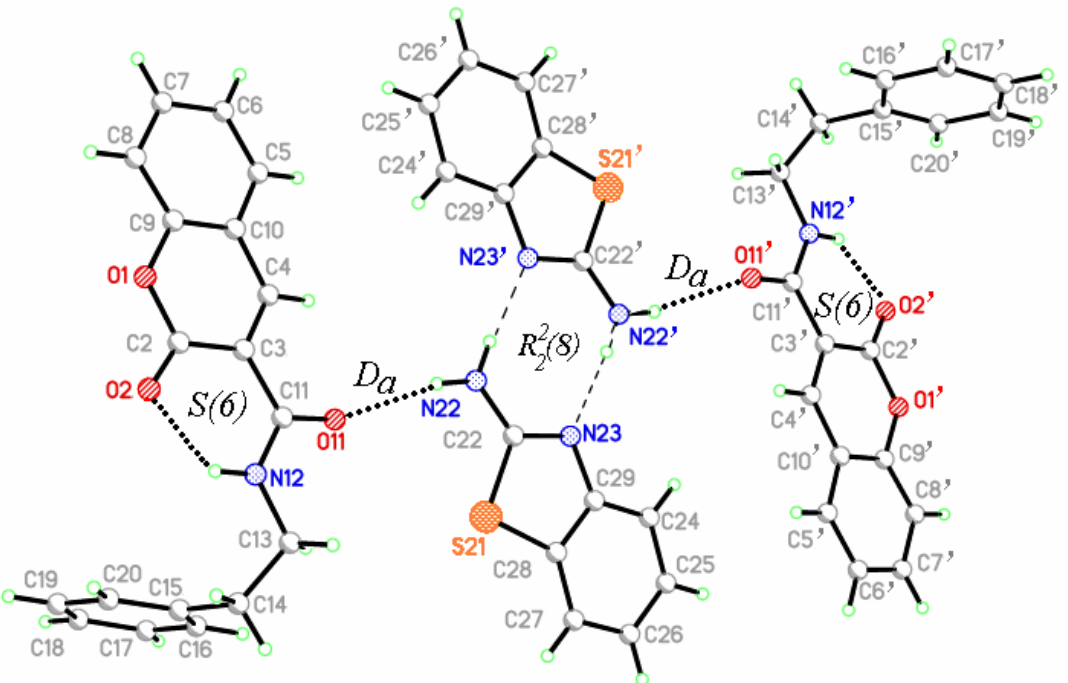

Figure 1. Supramolecular structure of the A $\cdots D^{\cdots} \cdots D^{\prime} \cdots A^{\prime}$ H-bonded pseudotetramer of complex 3.

The donor-acceptor interactions arise out of the crystal packing of this H-bonded pseudotetramer, to form the D-A complex shown in Figure 2. The donor and acceptor molecules are rotated by $49^{\circ}$ between each other (Figure $2 \mathrm{a}$ ) in relation to their long axes (C22-C26 and C2C6, respectively). This conformation generates a tilt between the donor and acceptor molecular planes of approximately $11^{\circ}$ in order to avoid the steric crowding caused by the larger sized sulphur atom. The mean interplanar distance between both molecules is $3.5 \pm 0.2 \AA$, in agreement 
to the values reported for other donor-acceptor complexes. ${ }^{15}$ The shortest intercentroid distance between the aromatic-donor ring $\mathrm{Cg}(2)$ and the lactone-acceptor ring $\mathrm{Cg}(3)$ of $3.513(1) \AA$ is very close to the interplanar distance of $3.34 \AA$ (see the previous structure block for ring numbering), resembling an almost face-to-face approach between these rings. In contrast, the intercentroid and interplanar distances as well as the interplanar angle $\gamma$ for the $C g(1)-C g(3)$ and $C g(2)-C g(4)$ interactions lie in the range corresponding to parallel displaced $(p d) \pi$-stacking interactions ${ }^{18}$ (Figure 2b, Table 2).

Table 1. H-bonding interactions observed for complex 3

\begin{tabular}{|c|c|c|c|c|}
\hline Interaction & $\begin{array}{l}\mathrm{X} \cdots \mathrm{Y}^{\mathrm{a}} \\
\text { distance/ } / \AA\end{array}$ & $\begin{array}{l}\mathrm{H}^{\cdots} \cdot \mathrm{Y}^{\mathrm{a}} \\
\text { distance } / \AA\end{array}$ & $\begin{array}{l}\mathrm{X}-\mathrm{H} \cdots \mathrm{Y}^{\mathrm{a}} \\
\text { angle }^{\circ}{ }^{\mathrm{a}}\end{array}$ & Motif $^{b}$ \\
\hline $\mathrm{N} 12-\mathrm{H} \cdots \mathrm{O} 2$ & $2.729(2)$ & 2.03 & 136 & $S(6)$ \\
\hline $\mathrm{N} 22-\mathrm{H} \cdots \mathrm{O} 11^{\mathrm{c}}$ & $2.869(2)$ & 2.14 & 140 & $D a$ \\
\hline $\mathrm{N} 22-\mathrm{H} \cdots \mathrm{N} 23^{\mathrm{d}}$ & $2.969(2)$ & 2.09 & 172 & $R_{2}^{2}(8)$ \\
\hline $\mathrm{C} 4-\mathrm{H} \cdots \mathrm{O} 2^{\mathrm{e}}$ & $3.371(2)$ & 2.50 & 153 & $C(5)$ \\
\hline $\mathrm{C} 5-\mathrm{H} \cdots \mathrm{O} 1^{\mathrm{e}}$ & $3.479(2)$ & 2.59 & 156 & $C(5)$ \\
\hline $\mathrm{C} 13-\mathrm{H} \cdots \mathrm{N} 23^{\mathrm{f}}$ & $3.378(2)$ & 2.55 & 141 & $D b$ \\
\hline $\mathrm{C} 6-\mathrm{H} \cdots \mathrm{Ph}^{\mathrm{g}}$ & $3.818(2)$ & 2.99 & 146 & $D c$ \\
\hline $\mathrm{C} 14-\mathrm{H} \cdots \mathrm{Cg}(1)^{\mathrm{f}}$ & $3.566(2)$ & 3.10 & 110 & $D d$ \\
\hline $\mathrm{C} 16-\mathrm{H} \cdots \mathrm{Bz}^{\mathrm{h}, \mathrm{i}}$ & $3.643(2)$ & 2.80 & 148 & $D e$ \\
\hline $\mathrm{C} 32-\mathrm{H} \cdots \mathrm{Cg}(2)^{\mathrm{f}}$ & $3.981(2)$ & 3.32 & 129 & $D f$ \\
\hline
\end{tabular}

${ }^{\mathrm{a}} \mathrm{Y}=\mathrm{O}$, N or aryl. ${ }^{\mathrm{b}}$ See reference 17 . Symmetry codes: ${ }^{\mathrm{c}}(1-\mathrm{x}, 1-\mathrm{y}, 1-\mathrm{z}),{ }^{\mathrm{d}}(-\mathrm{x}, 1-\mathrm{y}, 1-\mathrm{z}),{ }^{\mathrm{e}}(-$ $1+x, y, z),{ }^{f}(1+x, y, z),{ }^{g}(1-x,-y, 1-z),{ }^{h}(x, y, z) .{ }^{i} B z$ for benzene ring.

Table 2. Geometry of the $\pi$-stacking interactions in complex 3

\begin{tabular}{lllll}
\hline Interaction $^{\mathrm{a}}$ & $\begin{array}{c}\text { Intercentroid } \\
\text { distance/ } \AA\end{array}$ & $\begin{array}{c}\text { Interplanar } \\
\text { distance }^{\mathrm{b}} / \AA\end{array}$ & $\begin{array}{c}\alpha^{\mathrm{c}} \\
(\mathrm{deg})\end{array}$ & $\begin{array}{c}\gamma^{\mathrm{d}} \\
(\mathrm{deg})\end{array}$ \\
\hline $\mathrm{Cg}(1)-\mathrm{Cg}(3)^{\mathrm{e}}$ & $3.672(1)$ & 3.42 & 11.1 & 21.5 \\
$\mathrm{Cg}(2)-\mathrm{Cg}(3)^{\mathrm{e}}$ & $3.513(1)$ & 3.34 & 11.3 & 18.3 \\
$\mathrm{Cg}(2)-\mathrm{Cg}(4)^{\mathrm{e}}$ & $3.905(1)$ & 3.68 & 11.0 & 19.7 \\
$\mathrm{Cg}(3)-\mathrm{Cg}(4)^{\mathrm{f}}$ & $3.437(1)$ & 3.29 & 0.4 & 17.0 \\
\hline
\end{tabular}

${ }^{\mathrm{a}} \mathrm{Cg}(\mathrm{n})$ for centroid of ring $\mathrm{n}$, see the previous structure block for ring numbering.

${ }^{b}$ Perpendicular distance between the centroid of the first ring and the plane of the second ring. ${ }^{c}$ Dihedral angle between the plane of the first ring and the plane of the second ring.

${ }^{\mathrm{d}}$ Angle between the centroid of the first ring and the normal to the plane of the second ring. Symmetry codes: ${ }^{\mathrm{e}}(1-\mathrm{x}, 1-\mathrm{y}, 1-\mathrm{z}),{ }^{\mathrm{f}}(1-\mathrm{x},-\mathrm{y}, 1-\mathrm{z})$. 
Furthermore, two acceptor molecules are associated in an anti-tail-to-tail orientation through $p d$ - $\pi$-stacking interactions between $\mathrm{Cg}(3)$ and $\mathrm{Cg}(4)$ (Table 2). This arrangement is frequently observed for the self association of 3-carboxycoumarins. ${ }^{13}$ The $A-A^{\prime} \pi$-assembly formed (Figure $3 \mathrm{a}$ ), is also associated through $\mathrm{C} 6-\mathrm{H} \cdots \mathrm{Ph}$ interactions ${ }^{19}$ (Table 1). The angle between the phenethyl and coumarin ring mean planes is close to $93^{\circ}$ providing the length and flexibility required for this interaction to occur. Molecules of 2a are interlinked through $\mathrm{C} 4-\mathrm{H} \cdots \mathrm{O} 2$ and $\mathrm{C} 5-\mathrm{H} \cdots \mathrm{O} 1$ interactions (Table 1) and both develop $\mathrm{C}(5)$ chain motifs to form tapes that run along the parallel [033] planes (Figure 3b). This complex crystallizes with 0.5 equivalents of benzene which also appear $\mathrm{CH} / \pi$ associated (Table 1 ). Thus, the alternated D-A-A'-D' $\pi$-stacked assembly shown in Figure 4 is observed, which can be described as a host-guest complex composed of A-A' $\pi$-stacked homodimers intercalated between two layers of discrete H-bonded D'.D' homodimers.
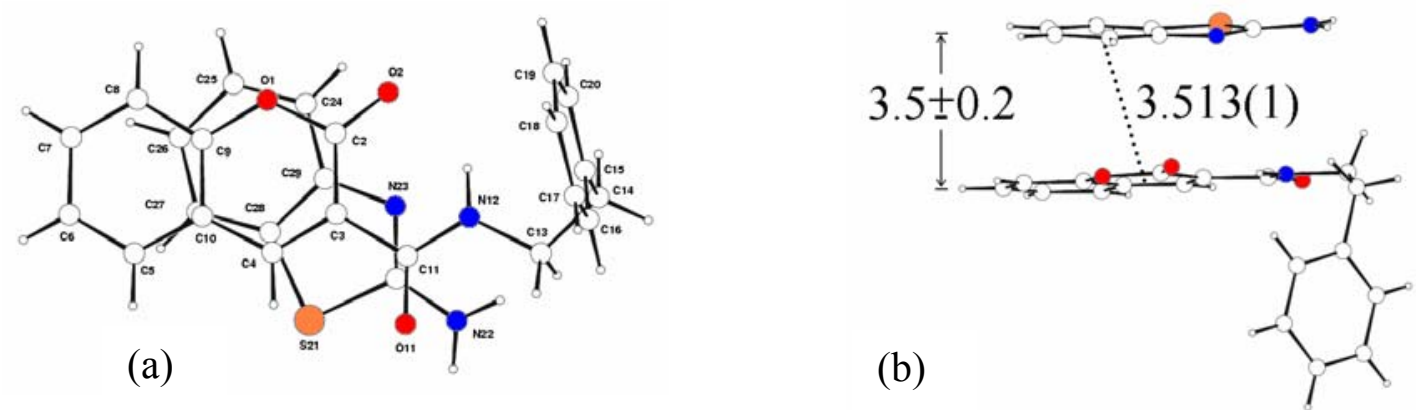

Figure 2. Part of the crystal structure of the D-A complex 3. (a) Top view, the twist angle between the two stacking molecules can be appreciated; (b) lateral view, the shortest intercentroid and the mean interplanar distances are shown.

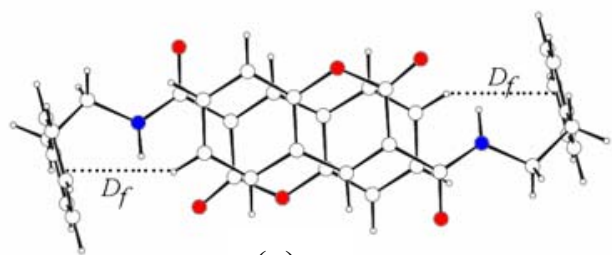

(a)

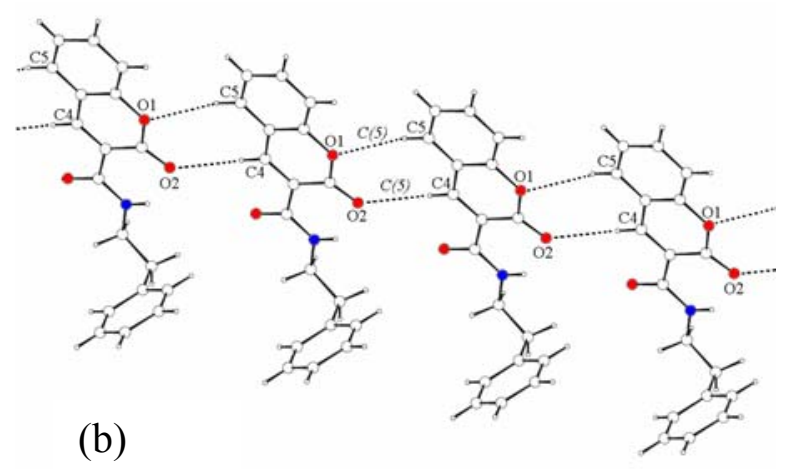

(b)

Figure 3. Part of the crystal structure of $\mathbf{3}$ showing the $\pi \mathrm{A}-\mathrm{A}^{\prime}$ self association. (a) Top view of the A-A' homodimer stacked in anti-tail-to-tail orientation; (b) coumarin C(5) H-bonding motifs in the [033] plane. 


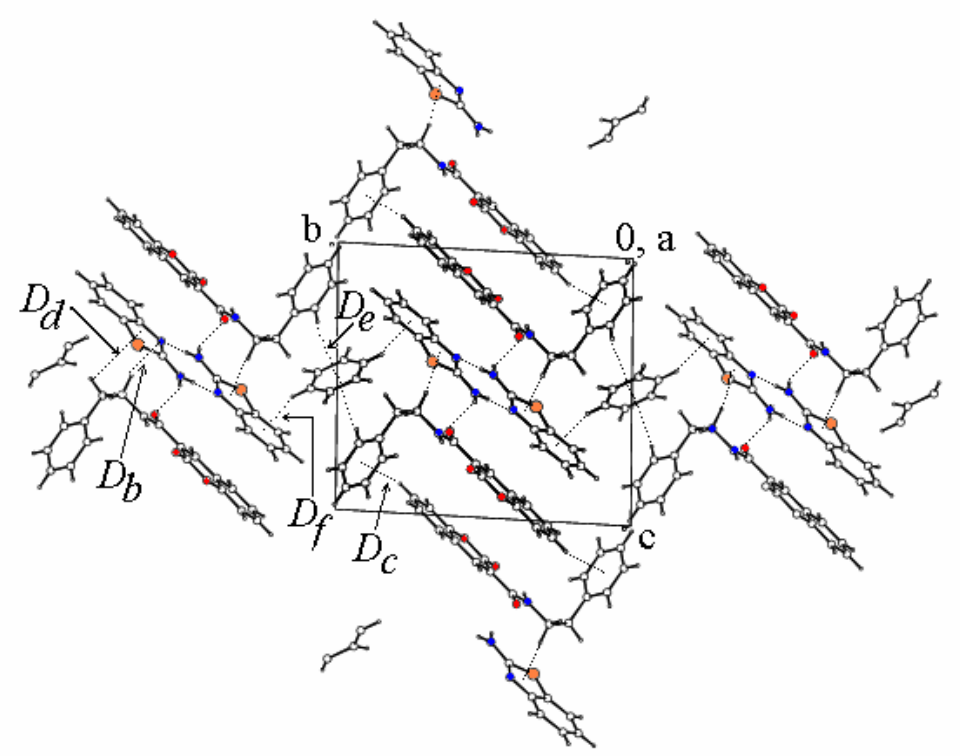

Figure 4. Supramolecular arrangement showing the D-A-A'-D' alternated $\pi$-stacking and the complete H-bonding scheme in the $b c$ plane.

\section{Comparison with other analogous complexes}

The crystal structure of 2-aminobenzothiazole- $N$-[(2-oxo-2H-1-benzopyran-3yl)carboxyl]benzylamide $4^{20}$ and 2-aminobenzothiazole-ethyl coumarin 3 -carboxylate $5^{21}$ donoracceptor complexes, have been reported elsewhere. Since these structures are closely related to $\mathbf{3}$, a brief comparison between them seems to be appropriate. The three complexes contain the hydrogen bonded $A \cdots D^{\prime} \cdots D^{\prime} \cdots A^{\prime}$ tetramer, however the $\pi$-stacking interactions are different: in the case of 3 and 4, a D-A-A'-D' stacking was found whereas in the case of 5, a D-A alternated stacking was observed.<smiles>O=C(NCc1ccccc1)c1cc2ccccc2oc1=O</smiles>

2b<smiles>CCOC(=O)c1cc2ccccc2oc1=O</smiles>

2c

4 Complex between $\mathbf{1}$ and $\mathbf{2 b}$

5 Complex between 1 and 2c

A common feature present in the three structures is the presence of the H-bonded D $\cdots D^{\prime}$ dimer as building block, which is formed by pair-wise self complementary $\mathrm{N}-\mathrm{H} \cdots \mathrm{N}$ interactions constituting an $R_{2}^{2}(8)$ motif. This $D^{\prime \cdots} D^{\prime}$ dimer is rather robust, since it has been observed in the crystal structure of free 2-aminobenzothiazole ${ }^{22 a}$ as well as in its molecular complexes with HMPA $^{22 b}$ and dimethylpropyleneurea. ${ }^{22}$ Its robustness is only disturbed by strong H-bonding 
interactions mainly with carboxylic acids, in most cases involving proton transfer from the carboxylic acid to the pyridine like nitrogen of the donor molecule. ${ }^{22-f}$ Therefore, is not surprising that the $\mathrm{D}^{\cdots} \mathrm{D}^{\prime} \mathrm{H}$-bonded dimer is preserved in complexes 3-5. This dimer is $\mathrm{H}$ bonded with acceptor molecules $2 \mathbf{a}-\mathbf{c}$ to form the characteristic $A \cdots D^{\cdots} \cdots D^{\prime} \cdots A^{\prime}$ tetramer found in these complexes.

The conformation between both carbonyl groups in the acceptor molecule has a determinant influence on both the twist angle between the donor and acceptor stacking and in the alternated stacking pattern observed. The antiperiplanar conformation between the two carbonyl groups in acceptors 2a-b favors a small twist angle (by $50^{\circ}$ ) between the $\pi$-stacked donor and acceptor, the D-A-A'-D' alternated stacking and the propagation of the intermolecular A $\cdots$ A H-bonding interactions along the $a$ direction through a $\mathrm{C}(5)$ chain motif. In contrast, the synperiplanar conformation of $2 \mathbf{c}$ imposes a wide twist angle $\left(111^{\circ}\right)$ as well as the alternated D-A $\pi$-stacking.

Finally, the capability of the acceptor to self associate has an effect on the observed alternated stacking pattern. The acceptors $\mathbf{2 a}$ and $\mathbf{2 b}$, bearing a pendant phenethyl or benzyl group, are self associated through $\mathrm{T}$-shaped interactions ${ }^{19}$ or through $\mathrm{Ph}$ - $\mathrm{Ph} \pi$-stacking interactions, respectively, thereby favoring the alternated D-A-A'-D' $\pi$-stacking pattern observed in complexes 3 and $\mathbf{4}$. In contrast, the alternated D-A $\pi$-stacking pattern is exhibited by complex $\mathbf{5}$, in which the possibility intermolecular H-bonding of $2 \mathrm{c}$ is missing.

Theoretical calculations. In order to gain more insight into the nature of the $\pi$-stacking interactions $^{23}$ involved in the formation of the supramolecular complexes analyzed herein, $a b$ initio molecular orbital calculations at $\mathrm{HF} / 6-31++\mathrm{G}$ level of theory were performed for donor $\mathbf{1}$, 3-carboxy amidocoumarin (3CA), as a model of acceptors $\mathbf{2 a - b}$, and for acceptor $\mathbf{2 c}$. The atomic charges were obtained according to the Merz-Kollman-Singh scheme (Figure 5) and the energies of the frontier orbitals, dipole moment and polarizabilities are listed in Table 3.

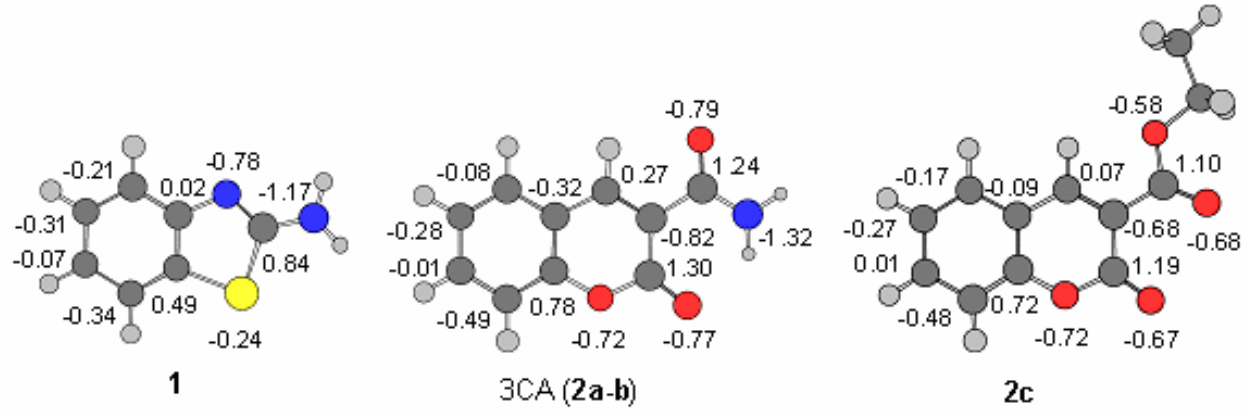

Figure 5. Electrostatic charges obtained according to the Merz-Kollman-Singh scheme at HF/6$31++\mathrm{G}$ level of theory for compounds 1, 3CA (model for molecules 2a,b) and 2c. 
Table 3. One electron properties and energies of the frontier molecular orbitals calculated at HF/6-31++G level theory for 1, 3-carboxyamido coumarin 3CA (model for molecules 2a-b) and 2c

\begin{tabular}{lccc}
\hline \multicolumn{1}{c}{ Property } & 1 & 3CA (2a-b) & 2c \\
\hline Energy of HOMO $(\mathrm{eV})$ & -8.32 & -9.54 & -9.37 \\
Energy of LUMO $(\mathrm{eV})$ & 1.05 & 0.61 & 0.66 \\
Dipole moment $\mu(\mathrm{D})$ & 1.46 & 5.04 & 8.73 \\
Polarizability $\alpha\left(\AA^{3}\right)$ & 23.26 & 26.66 & 28.13 \\
\hline
\end{tabular}

The donor molecule 1 presents strong positive charges for atoms C2 and C8 and strong negative charges for the two nitrogen atoms, whereas the coumarin-acceptors exhibit an alternated charge pattern in the lactone ring. These results are in agreement with low field ${ }^{13} \mathrm{C}$ NMR chemical shift measurements for these atoms in solution. ${ }^{24}$ The acceptor capability of 2a-c becomes evident upon comparison of the energies of their frontier MO with the energies of the frontier MO of donor 1. Both the HOMO and LUMO energies of coumarins 2a-c are more negative than those corresponding to compound $\mathbf{1}$. In addition, the acceptor molecules possess the larger dipole moments as well as the largest polarizabilities.

Accordingly to the theoretical calculations the association between molecules $\mathbf{1}$ and 2a-c seems to be favored by dispersion and charge transfer contributions. The repulsive and attractive electrostatic terms coming from different parts of the molecules compensate each other, leading to a more prominent participation of the overlap-dependent dispersion attraction. In contrast, the attractive electrostatic interactions appear to play a more important role in the self association between coumarins $\mathbf{2 b}$-c to form the $\pi$-stacked homodimers A-A'. These results are in agreement with those found by theoretical calculations for DNA-intercalators ${ }^{25 a}$ and DNA base pairs. ${ }^{25 b}$ It should be pointed out that, for all complexes studied herein, the shortest intercentroid distance corresponds to the interaction between the coumarin-lactone ring and the donor-benzenoid ring, furthermore, the mean interplanar distance between these two rings seems to define the magnitude of the CT interaction (3.50(3) $\AA$ and $399 \mathrm{~nm}, 3.5(2) \AA$ and $406 \mathrm{~nm}$, and 3.38(8) $\AA$ and $423 \mathrm{~nm}$ for the mean interplanar D-A distance and CT $\lambda_{\max }$ of complexes 3, 4 and 5, respectively), in agreement with the results found in non heterocyclic D-A complexes. ${ }^{15}$ The structural similarities between the H-bonded ABT-dimer and natural DNA base pairs, could help

to explain the teratogen ${ }^{26}$ and cytotoxic ${ }^{27}$ activities as well as gene mutation protection activity ${ }^{28}$ of several coumarin derivatives.

\section{Conclusions}

In summary, the molecular recognition found between 2 -aminobenzothiazole 1 and the 3 carboxy coumarin derivatives 2a-c opens new possibilities for crystal engineering of related solid 
structures and can be used as a model to study the interplay between H-bonding and $\pi$-stacking interactions in molecular recognition processes. The $\pi$-stacking patterns found in the donoracceptor complexes studied herein are of the D-A and D-A-A'-D' type, whereas the three dimensional supramolecular arrangement is achieved by both strong $\left(\mathrm{N}-\mathrm{H}^{\cdots} \mathrm{O}\right)$ and weak $\left(\mathrm{C}-\mathrm{H} \cdots \mathrm{X}, \mathrm{X}=\mathrm{O}\right.$, aryl) H-bonding interactions, which define an $\mathrm{A}^{\cdots} \mathrm{D}^{\mathrm{D}} \cdots \mathrm{D}^{\prime} \cdots \mathrm{A}^{\prime}$ tetrameric unit among other supramolecular units. The supramolecular isomerism exhibited by these complexes depends on: (i) the robustness of the H-bonded donor-dimer, (ii) the conformation between the two carbonyl groups of coumarin-molecules and (iii) their self association capability.

\section{Experimental Section}

General Procedures. Melting point was measured on an Electrothermal IA 9100 apparatus and is uncorrected. IR spectrum was recorded in $\mathrm{KBr}$ disc using a Perkin-Elmer 16F PC IR spectrophotometer. ${ }^{1} \mathrm{H}$ and ${ }^{13} \mathrm{C}$ NMR spectra were recorded on a Varian Mercury $300\left({ }^{1} \mathrm{H}\right.$, $\left.300.08 ;{ }^{13} \mathrm{C}, 75.46 \mathrm{MHz}\right)$ equipment in $\left[{ }^{2} \mathrm{H}_{6}\right] \mathrm{DMSO}$ solution, measured with $\mathrm{SiMe}_{4}$ as internal reference following standard techniques. UV-vis diffuse reflectance spectra were recorded on a CARY SE UV-VIS-NIR spectrophotometer with 0.1 molal samples in $\mathrm{KBr}$ discs (IR spectroscopic grade).

$\mathrm{X}$-ray structure of 3 . The X-ray data were measured on a Bruker Apex diffractometer with a $\mathrm{CCD}$ area detector using graphite-monochromated $\mathrm{Mo} \mathrm{K}_{\alpha}$ radiation $(0.71073 \AA)$. A total of 2424 frames (complete sphere) were collected via $\omega$-rotation $\left(\Delta \omega=0.3^{\circ}\right)$ at $10 \mathrm{~s}$ per frame (program Smart). ${ }^{29}$ The measured intensities were reduced to $F^{2}$ and corrected for absorption with SADABS (program SAINT-NT).$^{30}$ The cell parameters were determined by using reflections from all frames collected. The molecular structure was resolved by direct methods (SHELXS86). ${ }^{31}$ The WinGX (version 1.64.03a) ${ }^{32}$ software package was used for refinement and data output. The refinement was based on full-matrix least-squares methods, with anisotropic displacement parameters for all non-H atoms. Hydrogen atoms were fixed and refined using the riding model. The analysis of short contacts was realized using the PLATON ${ }^{33}$ program.

Crystal data for 3 with $\approx 0.5$ equivalents of $\mathrm{C}_{6} \mathrm{H}_{6}$. CCDC no. 218051, $\mathrm{C}_{28} \mathrm{H}_{24} \mathrm{~N}_{3} \mathrm{O}_{3} \mathrm{~S}, \mathrm{M}=482.6$, $a=6.6901(4), b=12.7297(8), c=14.1637(9) \AA, \alpha=91.074(1)^{\circ}, \beta=100.347(1)^{\circ}, \gamma=$ 98.638(1) $, \mathrm{U}=1171.85(3) \AA^{3}, \mathrm{~T}=173(2) \mathrm{K}$, space group $\mathrm{P}-1$ (no. 2$), \mathrm{Z}=2 ; \mu(\mathrm{Mo}-\mathrm{K} \alpha)=0.175$ $\mathrm{mm}^{-1}, 13624$ reflections measured, 5283 unique reflections $(\mathrm{Rint}=0.0327)$ which were used in all calculations. The final $\mathrm{wR}\left(\mathrm{F}^{2}\right)$ was 0.126 (all data).

Theoretical calculations. The structure of compounds 1, 3-carboxy amidocoumarin (as model for 2a-b) and 2c were optimized using the HF 6-31G basis set. The optimized geometries were found in close approach to the experimental crystal data. Thereafter, single point calculations at the HF $6-31++\mathrm{G}$ basis set were performed on the optimized structures to obtain the polarizability and potential-derived charges using the Merz-Kollman-Singh scheme. All calculations were done using the Gaussian98 program. ${ }^{34}$ 
$\mathrm{N}$-[(2-Oxo-2H-1-benzopyran-3-yl)carboxyl]phenethylamide (2a) was synthesized following reported procedures. ${ }^{24}$ 2-Aminobenzothiazole, chemicals and solvents were of reagent grade and used as received (Aldrich).

2-Aminobenzothiazole- $N$-[(2-oxo-2H-1-benzopyran-3-yl)carboxyl]phenethylamide cocrystals (3). Equimolar quantities of 2-aminobenzothiazole $1(2 \mathrm{mmol})$ and coumarin 2a $(2 \mathrm{mmol})$ were suspended in $15 \mathrm{~mL}$ of benzene. The resulting suspension was heated to the boiling point on a hot plate until complete solubilization. The homogeneous solution was allowed to cool to room temperature and after several days yellow crystals suitable for X-ray diffraction separated in almost quantitative yield. Mp 135-138 ${ }^{\circ} \mathrm{C}$. IR $(\mathrm{KBr}) v / \mathrm{cm}^{-1}: 3375(\mathrm{~N}-\mathrm{H}), 1705(\mathrm{C}=\mathrm{O}$ lactone), $1650\left(\mathrm{C}=\mathrm{O}\right.$ amide), $749(\mathrm{C}-\mathrm{S}) ;{ }^{1} \mathrm{H}$ NMR $\delta(\mathrm{ppm})$ (primes for ABT) : $8.85(\mathrm{~s}, 1 \mathrm{H}, \mathrm{H}-4), 8.76(\mathrm{t}$, 1H, NH), 7.96 (d, 1H, H-5), 7.73 (dd, 1H, H-7), 7.63 (d, 1H, H-7'), 7.47 (dd, 1H, H-6), 7.47 (d, 1H, H-8), 7.44 (s, 2H, NH 2 ), 7.31-7.21 (m, 5H, Ph), 7.30 (d, 1H, H-4'), 7.17 (dd, 1H, H-5'), 6.97 (dd, $1 \mathrm{H}, \mathrm{H}-6$ '), 3.55 (dt, $\left.2 \mathrm{H}, \mathrm{NCH}_{2}\right), 2.82\left(\mathrm{t}, 2 \mathrm{H}, \mathrm{PhCH}_{2}\right) ;{ }^{13} \mathrm{C}$ NMR $\delta$ (ppm) (primes for ABT): 166.4 (C-2'), 161.0 (C-11), 160.4 (C-2), 153.9 (C-9), 152.8 (C-9'), 147.5 (C-4), 138.1 (Ci), 134.1 (C-7), 130.9 (C-8'), 130.3 (C-5), 128.7 (Co), 128.4 (Cm), 126.2 (Cp), 125.4 (C-5'), 125.1 (C-6), 120.8 (C-7'), 120.8 (C-6'), 118.8 (C-3), 118.4 (C-10), 117.1 (C-4'), 116.1 (C-8), 40.7 $\left(\mathrm{NCH}_{2}\right), 34.9\left(\mathrm{CH}_{2} \mathrm{Ph}\right)$.

\section{Acknowledgments}

We thank Professor N. Barba-Behrens for access to the CARY SE spectrophotometer at the Facultad de Química UNAM, México. This work was supported by CONACYT-México (Grant 33438-E) and CGPI-IPN (Grant 5201).

\section{References}

1. Sharma, C. V. K. Cryst. Growth Des. 2002, 2, 465 and references cited therein.

2. Steiner, T. Angew. Chem. Int. Ed. 2002, 41, 48.

3. Broder, C. K.; Davidson, M. G.; Forsyth, V. T.; Howard, J. A. K.; Lamb, S.; Mason, S. A. Cryst. Growth Des. 2002, 2, 163 and references cited therein.

4. Bosch, E.; Radford, R.; Barnes, C. L. Org. Lett. 2001, 3, 881.

5. (a) Hunter, C. A. Angew. Chem. Int. Ed. Engl. 1993, 32, 1584. (b) Hunter, C. A. Chem. Soc. Rev. 1994, 101.

6. Cozzi, F.; Annunziata, R.; Banaglia, M.; Cinquini, M.; Raimondi, L.; Baldridge, K. K.; Siegel, J. S. Org. Biomol. Chem. 2003, 157 and references cited therein.

7. Coates, G. W.; Dunn, A. R.; Henling, L. M.; Ziller, J. W.; Lobkovsky, E. B.; Grubbs, R. H. J. Am. Chem. Soc. 1998, 120, 3641. 
8. Burger, A. Burger's Medicinal Chemistry, Wolff, M. E.; Ed.; Wiley Interscience: New York, 1995.

9. Orita, M.; Yamamoto, S.; Katayama, N.; Aoki, M.; Takayama, K.; Yamagiwa, Y.; Seki, N.; Suzuki, H.; Kurihara, H.; Sakashita, H.; Takeuchi, M.; Fujita, S.; Yamada, T.; Tanaka, A. J. Med. Chem. 2001, 44, 540.

10. Doucet, C.; Pochet, L.; Thierry, N.; Pirotte, B.; Delarge, J.; Reboud-Ravaux, M. J. Med. Chem. 1999, 42, 4161.

11. Pochet, L.; Doucet, C.; Schynts, M.; Thierry, N.; Boggeto, N.; Pirotte, B. J. Med. Chem. 1996, 39, 2579.

12. Brett, T. J.; Alexander, J. M.; Stezowski J. J. J. Chem. Soc., Perkin Trans 2 2000, 1095.

13. García-Báez, E.; Martínez-Martínez, F. J.; Höpfl, H., Padilla-Martínez, I. I. Cryst. Growth Des. 2003, 3, 35.

14. (a) Haining, R. L.; Jones, J. P.; Henne, K. R.; Fisher, M. B.; Koop, D. R.; Trager, W. F.; Rettie, A. E. Biochemistry 1999, 38, 3285. (b) Tsai, F. T. F.; Singh, O. M. P.; Skarzynski, T.; Wonacott, A. J.; Weston, S.; Trucker A.; Pauptit, R. A.; Breeze, A. L.; Poyser, J. P.; O’Brien, R.; Ladbury, J. E.; Wigley, D. B. Proteins 1997, 28, 41.

15. Rathore, R.; Lindeman, S. V.; Kochi, J. K. J. Am. Chem. Soc. 1997, 119, 9393.

16. Bosch, E.; Hubig, S. M.; Lindeman, S. V.; Kochi, J. K. J. Org. Chem. 1998, 63, 692.

17. (a) Etter, M. C. Acc. Chem. Res. 1993, 120. (b) Bernstein, J.; Davis, R. E.; Shimoni, L.; Chang, N. L. Angew. Chem. Int. Ed. Engl. 1995, 34, 1555. (c) Aakeröy, C. B.; Seddon, K. R. Chem. Soc. Rev. 1993, 397.

18. Sinnokrot, M. O.; Valeev, E. F.; Sherrill C. D. J. Am. Chem. Soc. 2002, 124, 10887.

19. Umezawa, Y.; Tsuboyama, S.; Honda, K.; Uzawa, J.; Nishio, M. Bull. Chem. Soc. Jpn. 1998, 71, 1207.

20. Martínez-Martínez F. J.; García-Báez, E. V.; Höpfl, H.; Padilla-Martínez, I. I. Acta Cryst. 2003, E59, o1628-o1630.

21. Padilla-Martínez, I. I.; García-Báez, E. V.; Höpfl, H.; Martínez-Martínez F. J. Acta Cryst. 2003, C59, o544.

22. (a) Goubitz, K.; Sonneveld, E. J.; Schenk, H. Z. Kristallogr. 2001, 216, 176. (b) Armstrong, D. R.; Bennett, S.; Davidson, M. G.; Snaith, R.; Stalke, D.; Wright, D. S. Chem. Commun. 1992, 262. (c) Armstrong, D. R.; Davidson, M. G.; Martin, A.; Raithby, P. R.; Snaith, R.; Stalke, D. Angew. Chem. Int. Ed. Engl. 1992, 31, 1634. (d) Lynch, D. E.; Cooper, C. J.; Chauhan, V.; Smith, G.; Healy, P.; Parsons S. Aust. J. Chem. 1999, 52, 695. (e) Lynch, D. E.; Nicholls, L. J.; Smith, G.; Byriel, K. A.; Kennard, C. H. L. Acta Cryst. 1999, B55, 758. (f) Lynch, D. E.; Smith, G.; Byriel, K. A.; Kennard, C. H. L. Aust. J. Chem. 1998, 51, 587.

23. (a) Williams, J. H. Acc. Chem. Res. 1993, 26, 593. (b) Hunter, C. A.; Singh, J.; Thornton, J. M. J. Mol. Biol. 1991, 218, 837. (c) Singh, J.; Thornton, J. M. J. Mol. Biol. 1990, 211, 595. (d) Dance, I.; Scudder, M. Chem. Eur. J. 1996, 2, 481.

24. Martínez-Martínez, F. J.; Padilla-Martínez, I. I.; Trujillo-Ferrara, J. Magn. Res. Chem. 2001, $39,765$. 
25. (a) Řeha, D.; Kabeláč, M.; Ryjáček, F.; Šponer, J.; Šponer, J. E.; Elstner, M.; Suhai, S.; Hobza, P. J. Am. Chem. Soc. 2002, 124, 3366 and references cited therein. (b) Bugg, C. E.; Thomas, J. M.; Sundaralingam, M.; Rao, S. T. Biopolymers 1971, 10, 175.

26. Driel, D. V.; Wesseling, J.; Sauer, P. J. J.; Touwen, B. C. L.; Der-Veer, E. V.; Heymans, H. S. A. Teratology 2002, 66, 127.

27. Kostova, I.; Manolov, I.; Karaivanova, M. Arch. Pharm. 2001, 334, 157.

28. Goeger, D. E.; Anderson, K. E.; Hsie, A. W. Environmental and Molecular Mutagenesis, 1998, 32, 64.

29. Bruker Analytical X-ray Systems, SMART, Bruker Molecular Analysis Research Tool V.5.618, 2000.

30. Bruker Analytical X-ray Systems, SAINT-NT version 6.04, 2001.

31. Sheldrick, G. M. SHELXS-86, Program for Crystal Structure Solution, University of Göttingen, Germany, 1986.

32. Farrugia, L. J. J. Appl. Cryst. 1999, 32, 837.

33. Spek, A. L. PLATON, Program for Crystal Structure Results Analysis, Bijvoet Center for Biomolecule Research, Vakgroep Kristal-en Structure-Chemie, University of Utrecht, The Netherlands.

34. Frisch, M. J.; Trucks, G. W.; Schlegel, H. B.; Scuseria, G. E.; Robb, M. A.; Cheeseman, J. R.; Zakrzewski, V. G.; Montgomery, Jr., J. A.; Stratmann, R. E.; Burant, J. C.; Dapprich, S.; Millam, J. M.; Daniels, A. D.; Kudin, K. N.; Strain, M. C.; Farkas, O.; Tomasi, J.; Barone, V.; Cossi, M.; Cammi, R.; Mennucci, B.; Pomelli, C.; Adamo, C.; Clifford, S.; Ochterski, J.; Petersson, G. A.; Ayala, P. Y.; Cui, Q.; Morokuma, K.; Malick, D. K.; Rabuck, A. D.; Raghavachari, K.; Foresman, J. B.; Cioslowski, J.; Ortiz, J. V.; Baboul, A. G.; Stefanov, B. B.; Liu, G.; Liashenko, A.; Piskorz, P.; Komaromi, I.; Gomperts, R.; Martin, R. L.; Fox, D. J.; Keith, T.; Al-Laham, M. A.; Peng, C. Y.; Nanayakkara, A.; Gonzalez, C.; Challacombe, M.; Gill, P. M. W.; Johnson, B.; Chen, W.; Wong, M. W.; Andres, J. L.; Gonzalez, C.; Head-Gordon, M.; Replogle, E. S.; J. A. Pople, Gaussian 98 (Revision A.7), Pittsburgh PA, 1998. 